\title{
Non-small cell lung cancer (NSCLC) and central nervous system (CNS) metastases: role of tyrosine kinase inhibitors (TKIs) and evidence in favor or against their use with concurrent cranial radiotherapy
}

\author{
Panagiota Economopoulou $^{1}$, Giannis Mountzios ${ }^{2}$ \\ ${ }^{1}$ Department of Medical Oncology, Attikon University Hospital, Athens, Greece; ${ }^{2}$ Department of Medical Oncology, 251 Airforce General Hospital, \\ Athens, Greece \\ Contributions: (I) Conception and design: All authors; (II) Administrative support: G Mountzios; (III) Provision of study materials or patients: P \\ Economopoulou; (IV) Collection and assembly of data: P Economopoulou; (V) Data analysis and interpretation: All authors; (VI) Manuscript \\ writing: All authors; (VII) Final approval of manuscript: All authors. \\ Correspondence to: Giannis Mountzios. Department of Medical Oncology, 251 Airforce General Hospital, Athens, Greece. Email: gmountzios@gmail.com.
}

\begin{abstract}
Central nervous system (CNS) metastases, including brain metastases (BM) and leptomeningeal metastases (LM) represent a frequent complication of non-small cell lung cancer (NSCLC). Patients with $\mathrm{BM}$ comprise a heterogeneous group, with a median survival that ranges from 3 to 14 months. However, in the majority of patients, the occurrence of CNS metastases is usually accompanied by severe morbidity and substantial deterioration in quality of life. Local therapies, such as whole brain radiotherapy (WBRT), stereotactic radiosurgery (SRS) or surgical resection, either alone or as part of a multimodality treatment are available treatment strategies for BM and the choice of therapy varies depending on patient group and prognosis. Meanwhile, introduction of tyrosine kinase inhibitors (TKIs) in clinical practice has led to individualization of therapy based upon the presence of the exact abnormality, resulting in a major therapeutic improvement in patients with NSCLC who harbor epidermal growth factor receptor (EGFR) activating mutations or anaplastic lymphoma kinase (ALK) gene rearrangements, respectively. Based on their clinical activity in systemic disease, such molecular agents could offer the promise of improved BM control without substantial toxicity; however, their role in combination with radiotherapy is controversial. In this review, we discuss the controversy regarding the use of TKIs in combination with radiotherapy and illustrate future perspectives in the treatment of BM in NSCLC.
\end{abstract}

Keywords: Non-small cell lung cancer (NSCLC); central nervous system metastases (CNS metastases); tyrosine kinase inhibitors (TKIs); concurrent radiotherapy

Submitted Aug 14, 2016. Accepted for publication Oct 08, 2016.

doi: 10.21037/tlcr.2016.12.06

View this article at: http://dx.doi.org/10.21037/tlcr.2016.12.06

\section{Introduction}

Non-small cell lung cancer (NSCLC), which accounts for $84 \%$ of lung cancer cases in the US, is one of the major causes of cancer-related deaths worldwide (1). Central nervous system (CNS) metastases, including brain metastases (BM) and leptomeningeal metastases (LM) represent a frequent complication; it has been postulated that approximately $40 \%$ and $5 \%$ of NSCLC patients will develop BM and LM respectively during the course of the disease (2). Patients with BM comprise a heterogeneous group, with a median survival that ranges from 3 to 14 months (3). However, in the majority of patients, the occurrence of CNS metastases is usually accompanied by severe morbidity and decrease in quality of life. 
Through the years, advances in evaluation of BM, such as the development of the Diagnosis-Specific Graded Prognostic Assessment (GPA) score enabled quantification of prognosis and assessment of patient survival (4). Local therapies, such as whole brain radiotherapy (WBRT), stereotactic radiosurgery (SRS) or surgical resection, either alone or as part of multimodality treatment are available treatment strategies for BM and the choice of therapy varies depending on patient group and prognosis. On the other hand, the role of systemic therapy in the treatment of patients with BM is less well-defined. Recent studies assessing the efficacy of chemotherapeutic agents, such as temozolomide, in combination with radiotherapy in patients with NSCLC and BM have failed to demonstrate any benefit compared to radiotherapy alone, possibly as a result of low blood brain barrier (BBB) penetration $(5,6)$. However, several prospective trials in NSCLC patients with asymptomatic BM haves shown substantial activity of first line chemotherapy for BM, with intracranial response rates (RR) comparable to systemic RR, warranting further research on the role of chemotherapy in CNS disease from NSCLC (7-12).

Most recently, an improved understanding of the molecular pathways that drive malignancy in NSCLC triggered the development of agents that act against specific molecular targets in cancer cells, such as epidermal growth factor receptor (EGFR) and anaplastic lymphoma kinase (ALK). Introduction of tyrosine kinase inhibitors (TKIs) in clinical practice has led to individualization of therapy based upon the presence of the exact abnormality, resulting in a major therapeutic improvement in patients with NSCLC who harbor EGFR or ALK activating mutations. Based on their clinical activity in systemic disease, such molecular agents could offer the promise of improved BM control without substantial toxicity; however, their role in combination with radiotherapy is controversial.

In this review, we will discuss the controversy regarding the use of TKIs in combination with radiotherapy and illustrate future perspectives in the treatment of BM in NSCLC.

\section{CNS metastases in NSCLC: current clinical practice}

CNS metastases are present at initial diagnosis in approximately $10-20 \%$ of patients with NSCLC. Furthermore, it has been estimated that they develop as site of first recurrence following successful locoregional treatment for non-metastasized locally advanced NSCLC in approximately $18 \%$ of NSCLC patients (13). Traditionally, systemic therapies have a limited role in the treatment of CNS metastases, due to presence of a BBB that prevents systemic drugs from reaching brain parenchyma. The $\mathrm{BBB}$ is formed by brain endothelial cells connected by tight junctions with high electrical resistivity and acts as a selective barrier between the systemic circulation and cerebrospinal fluid (CSF) (14). BBB is surrounded by a basement membrane covered by podocytes and astrocytes. It permits the passage of lipid-soluble molecules by passive diffusion, in addition to molecules essential for neural function. Selective chemotherapeutic drugs that are able to achieve good BBB penetration are those that are not substrates of efflux transporters, such as P-glycoprotein, which is high expressed by the BBB and carries the majority of drugs outside the intracranial region (15). Nevertheless, the integrity of $\mathrm{BBB}$ is usually disrupted following the occurrence of $\mathrm{BM}$ at later stages, albeit permeability is inhomogeneous (16). More specifically, when BM reach a size more than $5 \mathrm{~mm}$, the $\mathrm{BBB}$ is disrupted, as demonstrated by enhancement upon intravenous contrast medium injection during imaging techniques (12). In addition, WBRT commonly disrupts the BBB. The disruption of the $\mathrm{BBB}$ might explain the activity of first line chemotherapy in NSCLC BM (12). However, BM is frequently the site of relapse after curative treatment in NSCLC; this indicates that chemotherapeutic drugs might not sufficiently cross the BBB.

Initial therapy for symptomatic BM includes the administration of corticosteroids to reduce peri-tumoral edema and anticonvulsant therapies in case of seizures (17). Subsequently, treatment depends on the location, number of BM and prognosis. Patients with a single brain metastasis who are good surgical candidates should be offered surgical resection or SRS, as several studies have shown a survival advantage with the addition of surgery or SRS to WBRT compared to WBRT alone (18-20). Patients with 1-4 cerebral metastases should be treated with SRS with or without WBRT. The combination of SRS and WBRT has been shown to improve intracranial control but not overall survival (OS) in patients with oligo metastatic or oligo progressive disease $(21,22)$. On the other hand, the vast majority of patients are not eligible for invasive strategies due to multiple metastases or poor performance status. WBRT represents the only therapeutic option for these patients; it results in improvement of neurological deficits in approximately $30 \%$ of patients (23). However, 
in the recent randomized QUARTZ trial, that assessed the efficacy of WBRT compared to best supportive care in patients with BM and NSCLC, no clear survival advantage or improvement in quality of life was shown for patients that were treated with WBRT (24).

There is currently no standard of care for the treatment of LM; this is mainly due to the fact that LM occurs relatively rarely. Consequently, there is a lack of randomized studies; available therapeutic options, such as intravenous or intrathecal chemotherapy and radiation of the brain or affected neuro-axis are somewhat based on the treatment of patients with LM and hematological malignancies. In either case, patients with LM carry a dismal prognosis that ranges from 4 to 22 weeks $(25,26)$.

\section{TKIs and NSCLC-associated BM}

\section{EGFR TKIs}

EGFR TKIs, such as erlotinib, gefitinib and afatinib are the standard therapy for advanced NSCLC patients with EGFR-activating mutations, having shown superiority in progression free survival (PFS) compared to chemotherapy as first line treatment (27-29). There is relative controversy regarding the change of EGFR mutational status during the metastatic process; several studies suggest a poor correlation (30,31), while others have shown consistency between EGFR mutations found in the primary tumor and corresponding BM (32). At present, there is some retrospective evidence supporting a higher incidence of $\mathrm{BM}$ in EGFR mutant tumors (33); however, it is unclear whether there is a difference at initial diagnosis. Most importantly, EGFR mutant tumors are more likely to develop BM during the course of the disease mainly due to longer life expectancy. On the other hand, it has been postulated that approximately $14-17 \%$ of patients with EGFR mutant NSCLC present with isolated CNS progression after front line treatment with EGFR TKIs (34-37). However, others have demonstrated a lower incidence of BM in the same population (38). In a retrospective report by Heon et al., patients with EGFR mutant NSCLC treated with front line erlotinib and gefitinib had a lower rate of CNS progression compared with patients treated with chemotherapy [21\% vs. $32 \%$ at 1 year, $\mathrm{HR}=0.56 ; 95 \%$ confidence interval $(\mathrm{CI})$, $0.34-0.94]$ (39).

In contrast to cytotoxic agents, EGFR TKIs have been shown to cross the BBB. This might be attributed to their low molecular weight; however, concentration in the
CSF is generally much lower than in blood circulation, which partially hampers their ability to reach the brain parenchyma $(40,41)$. Interestingly, higher concentrations are achieved with erlotinib than gefitinib, suggesting an increased efficacy of erlotinib in treating BM (40).

Several case reports have postulated complete and continuous responses following treatment of BM with gefitinib or erlotinib (42-44). Furthermore, gefitinib has clinical activity as monotherapy in unselected patients with NSCLC and BM after failure of standard therapy (45). In patients with EGFR mutant tumors, retrospective data suggest an overall intracranial response of $89 \%$ for gefitinib and $82 \%$ for erlotinib $(2,14,46)$. Interestingly, erlotinib has been investigated as monotherapy in the management of BM. Gerber et al. retrospectively analyzed data from 222 patients with EGFR mutant tumors and newly diagnosed $\mathrm{BM}$ who were treated with either erlotinib, WBRT or SRS. WBRT was associated with better intracranial control, albeit similar OS compared to erlotinib. In this study, the authors underlined the importance of WBRT in achieving local control of BM (47). In another phase II trial, erlotinib was evaluated as second line therapy in NSCLC patients with asymptomatic $\mathrm{BM}$ and no extracranial progressive disease following first line platinum-based chemotherapy treatment. The median intracranial PFS was 15.2 months for patients with EGFR positive tumors, albeit only 4.4 months for EGFR unselected patients. It is important to note that a series of phase I/II studies using high dose erlotinib for the treatment of LM in patients with NSCLC has shown both efficacy and tolerability $(48,49)$. On the other hand, second generation TKI afatinib has also shown clinical activity against BM. In a study by Hoffknecht et al., afatinib demonstrated a disease control rate (DCR) of $66 \%$ in NSCLC patients with BM pretreated with chemotherapy and first generation TKIs (50).

Finally, third generation irreversible EGFR TKI osimertinib, which has been proven effective against EGFRmutant tumors with acquired T790M resistance, has shown substantial CNS penetration and remarkable CNS activity both at preclinical and clinical level (phase II data) (51-53). Furthermore, in the recent I BLOOM study that was presented in the 2016 ASCO annual meeting and included 21 patients with LM from NSCLC, osimertinib provided LM disease control in $76 \%$ of patients, among which $33 \%$ had radiologic improvement (54). The majority of patients were heavily pretreated.

Of note, there is a question whether there is a potential role of prophylactic cranial irradiation (PCI) in patients 
with EGFR-mutant tumors that are characterized by a higher incidence of BM. In a recent report, patients with L858R mutations have been found to have a greater risk of developing BM (55). There are no randomized studies addressing this issue. A recent study has shown a potential benefit of PCI in patients with surgically resected stage IIIA-N2 NSCLC and high risk of BM after adjuvant chemotherapy (56); however, this study does not provide data on EGFR mutations.

\section{ALK-TKIs}

Rearrangement of ALK is seen in approximately 2-7\% of patients with NSCLC and is a therapeutic target in advanced NSCLC. It is not clear whether patients with ALK positive tumors present more frequently with BM at initial diagnosis; however, it has been estimated that $60 \%$ of patients develop CNS metastases during treatment with first generation TKI crizotinib (57). Several reports suggest a very low CSF to plasma concentration ratio for crizotinib $(58,59)$. In a retrospective analysis of patients with BM included in the pivotal trials PROFILE 1005 and PROFILE 1007 that let to approval of crizotinib as first and second line treatment in ALK positive NSCLC, crizotinib showed an intracranial RR of $18 \%$ in untreated $\mathrm{BM}$ and $33 \%$ in pretreated $\mathrm{BM}$, compared to $50 \%$ overall response rate (ORR) in systematic disease (60). Furthermore, patients with no preexisting CNS disease developed BM in $20 \%$ of cases, while progressive disease in the CNS occurred in $71.1 \%$ of patients with known BM at baseline. Based on data of poor CNS activity of crizotinib, it is suggested that patients experiencing CNS progression on crizotinib should be offered local CNS therapies whereas the administration of crizotinib should be continued.

Novel ALK-TKIs such as ceritinib and alectinib have shown promising activity against BM. In a recent report, efficacy and safety of ceritinib was assessed in a subset of patients with $\mathrm{BM}$ in the phase I ASCEND-1 trial. Among 14 patients with BM, 7 had intracranial response, 4 of which have been previously treated with crizotinib (61). On the other hand, alectinib has been designated by the FDA as breakthrough therapy, following the high RR it demonstrated in the phase I/II trial in crizotinib-naïve ALK positive NSCLC patients (62). Alectinib has a better $\mathrm{BBB}$ penetration than crizotinib because it is not expelled by $\mathrm{P}$-glycoprotein from the intracranial environment (57). In a phase II trial conducted in crizotinib-resistant or intolerant patients, 21 patients had BM; alectinib achieved a $52 \%$ RR (63). Furthermore, among for patients who have not received WBRT, CNS control was $100 \%$ with alectinib. This trial provides evidence that alectinib is active in $\mathrm{BM}$ after failure of crizotinib. However, prospective comparison across ALK-TKIs regarding CNS activity is hampered by lack of CSF pharmacokinetic measurements. The randomized phase III ALEX trial is currently assessing the efficacy of alectinib vs. crizotinib as front line treatment in ALK positive NSCLC; its design will allow discriminate between intracranial and extracranial failure. Finally, activity of ALK-TKIs in LM is anecdotal $(63,64)$; results are eagerly expected from ongoing phase III trials ALEX and ASCEND-7, which include patients with LM (NCT02075840, NCT02336451).

\section{TKIs with concurrent radiotherapy}

\section{Rationale and clinical data}

The management of $\mathrm{BM}$ continues to pose a major challenge in oncology and current therapeutic options have modest results in achieving good or long intracranial responses. WBRT is the mainstay of treatment for patients with multiple metastases. According to NCCN guidelines, patients with poor performance status should receive a shorter course of WBRT. EGFR and ALK TKIs have demonstrated good clinical activity in systemic disease and might delay CNS progression in patients with EGFR mutant and ALK positive tumors respectively. However, in patients with driver mutations, whether EGFR-TKIs can enhance or replace cranial irradiation in the initial treatment of BM remains unclear. In a recent meta-analysis, upfront radiation therapy was shown to improve intracranial disease control and survival compared to TKI monotherapy in patients with EGFR mutant tumors (65). In this meta-analysis, a small proportion of patients received a combination of WBRT and EGFR TKI. On the other hand, there is evidence that sequential use of TKIs can delay administration of WBRT in EGFR mutant tumors (66). An intriguing question in clinical practice is whether a TKI could be safely combined with WBRT and in which patient population.

Preclinical data support the combined use of radiotherapy and EGFR inhibitors as a strategy for cancer treatment. In the clinical setting, anti-EGFR monoclonal antibody cetuximab has been suggested as a radiosensitizer, demonstrating improved OS in conjunction with radiation compared to radiation alone in patients with squamous cell carcinoma of the head and neck (67), albeit having failed to show any 
benefit in combination with chemoradiation in locally advanced NSCLC (68). On the other hand, EGFR TKIs have shown to potentiate radiotherapy response in human carcinoma cell lines in vivo and in vitro $(69,70)$. Potential mechanisms of synergism include cell cycle arrest, induction of apoptosis, inhibition of radiation-induced DNA repair mechanisms and increased EGFR expression in radioresistant clones (69-71). In addition, radiotherapy might disrupt the $\mathrm{BBB}$, facilitating passage of drugs into the brain (72).

A dose-escalation phase I trial reported by Lind et al. evaluated the tolerability of WBRT with concurrent and maintenance erlotinib in an unselected population of patients with NSCLC and BM (73). Patients in cohort 1 received erlotinib at a dose of $100 \mathrm{mg} / \mathrm{d}$ before and during WBRT, whereas in cohort 2, erlotinib was administered at a dose of $150 \mathrm{mg} / \mathrm{d}$ before and during WBRT; patients in both subgroups received maintenance erlotinib at a dose of $150 \mathrm{mg} / \mathrm{d}$. Out of 11 patients, no serious treatment related toxicity was observed in cohort 1 ; however, in cohort 2 , one patient developed grade 3 rash, one had grade 3 fatigue and two patients died of interstitial lung disease attributed to erlotinib. No neurotoxicity was reported. Interestingly, only one patient experienced intracranial progression, suggesting a high intracranial disease control (73).

Following the results of the phase I study, a phase II study was conducted in patients with NSCLC and newly diagnosed BM regardless of EGFR status (74). Erlotinib was given at a dose of $150 \mathrm{mg} / \mathrm{d}$ one week before and concurrently with WBRT followed by maintenance. ORR was $86 \%$ in the whole population and median survival was 11.8 months, significantly longer than historical controls. No neurotoxicity was noted. As expected, median PFS and OS were longer in patients with EGFR mutant tumors [PFS: 12.3 vs. 5.2 months and OS: 19.1 vs. 9.3 months in EGFR wild type (WT) tumors]. This is in concordance with a recent retrospective study that showed an excellent intracranial control and a median OS of 26 months in patients with EGFR mutant tumors treated with WBRT plus EGFR-TKIs (75).

A phase III trial was subsequently performed by the Radiation Therapy Oncology Group (RTOG) evaluating the addition of temozolomide or erlotinib in combination with WBRT and SRS in patients with 1-3 BM and unselected EGFR status (76). The study closed early due to accrual limitations. Median survival was numerically longer with WBRT + SRS compared to WBRT + SRS and temozolomide, or WBRT + SRS and erlotinib (13.1 vs. 6.3 vs. 6.1 months respectively) albeit not statistically significant. This deleterious effect in survival was possibly attributed to increased grade 3 to 5 toxicity in the combination arms, which reached $49 \%$ with the addition of erlotinib $(\mathrm{P}<0.001)(76)$.

In a subsequent randomized, placebo controlled phase II study, patients were treated with WBRT with or without erlotinib in a population of predominantly EGFR-WT patients (77). In this study, only $37.5 \%$ of patients were alive and without neurological progression following WBRT and no advantage in neurological PFS or OS was observed with the addition of erlotinib (PFS and OS HR $=0.95$ ). This is the only study demonstrating an absence of efficacy of erlotinib in combination with WBRT in EGFR WT patients. This was confirmed in a recent meta-analysis presented in the 2015 ASCO meeting; in an unselected population of patients with BM, the addition of EGFRTKIs to WBRT did not provide significant benefit (78).

Gefitinib has also been evaluated in combination with WBRT in phase II trials. In a phase II study conducted in a Chinese population, gefitinib was administered in combination with WBRT, followed by maintenance therapy (79). The study showed promising results; ORR was $86 \%$ and OS was 13 months. Most side effects were grade II (rash, diarrhea) and well tolerated. In another randomized phase II trial, patients with NSCLC and BM were treated with WBRT in combination with either gefitinib or temozolomide (80). Median OS was 6.3 months in the gefitinib-WBRT group compared to 4.9 months in the temozolomide-WBRT group. No significant toxicity was observed. Concomitant use of gefitinib and WBRT is further supported by a retrospective analysis that included Chinese patients with BM who were treated with gefitinib with or without WBRT (81). Patients in the combination group demonstrated a superior intracranial DCR, median time to progression of BM and median OS $(71.1 \%, 10.6$ and 23.40 months respectively in the gefitinib-WBRT vs. $42.2 \%, 6.57$ and 14.83 months respectively in the gefitinibonly group). Nevertheless, these two studies both involve a Chinese population with known intrinsic sensitivity to gefitinib; it is unclear whether results can be generalized in the European population. Of note, no studies assessing the efficacy of afatinib with WBRT have been performed.

The results of those trials were assessed in two recent meta-analyses, designed to evaluate the efficacy and safety of the use of EGFR TKIs with concurrent intracranial radiotherapy in patients with NSCLC and BM. The first meta-analysis, which included 8 studies, demonstrated a superior ORR ( $\mathrm{HR}=1.56, \mathrm{P}=0.0008$ ) and time to CNS progression $(\mathrm{HR}=0.58, \mathrm{P}=0.03)$ in patients treated with 
WBRT in combination with an EGFR-TKI (TKI-group) compared with patients treated with WBRT without an EGFR-TKI (non-TKI group) (82). Furthermore, no difference in severe adverse events was shown $(\mathrm{HR}=1.49$, $\mathrm{P}=0.14)$. The second meta-analysis that included 15 studies had similar results; radiotherapy plus an EGFR TKI resulted in improved $\mathrm{RR}$ and $\mathrm{DCR}(\mathrm{RR}=1.48 ; 95 \% \mathrm{CI}$, $1.12-1.96 ; \mathrm{P}=0.005$; and $\mathrm{DCR}=1.29 ; 95 \% \mathrm{CI}, 1.02-1.60$; $\mathrm{P}=0.035$; respectively) than radiotherapy without an EGFR-TKI (83). Moreover, time to CNS progression and median OS were both prolonged ( $\mathrm{HR}=0.56 ; 95 \% \mathrm{CI}$, $0.33-0.80 ; \mathrm{P}=0.000$ and $\mathrm{HR}=0.58 ; 95 \% \mathrm{CI}, 0.42-0.74$; $\mathrm{P}=0.000$ respectively), albeit with an increased rate of any grade adverse events $(\mathrm{RR}=1.25 ; 95 \% \mathrm{CI}, 1.01-1.57$; $\mathrm{P}=0.009$ ), especially rash and dry skin. The results of these meta-analyses should be interpreted with caution, due to heterogeneity of the included studies and different treatment modalities combined.

With regards to ALK-TKIs, there is currently no evidence in favor or against their concomitant use with radiotherapy. However, concurrent use should be applied with caution, as it is possible that concurrent radiotherapy could exacerbate ocular toxicity of crizotinib (84).

Clinical trials of radiotherapy plus TKIs in patients with NSCLC and BM are summarized in Table 1.

\section{Expert opinion}

The paradigm shift occurring in NSCLC is encapsulated by the management of patients harboring activating mutations. In patients with EGFR mutant or ALK positive tumors, front line treatment with EGFR or ALK inhibitors results in high systemic RRs and a lower risk of CNS progression. However, isolated or predominant CNS progression represents a major issue in patients treated with EGFR or ALK TKIs, regardless of impressive initial response. In an attempt to increase intracerebral efficacy, concurrent use of TKIs and radiotherapy is undoubtedly a tempting approach. Advantages would be the possible synergistic antitumor effect against BM, as suggested in preclinical studies, as well as prevention of disease flare, which refers to accelerated progression of disease and subsequent worsening of symptoms following TKI discontinuation (85).

At present, several clinical studies and meta-analyses have shown superior clinical activity in BM with the combination of WBRT and TKIs. However, there are many limitations that need to be addressed. First, most of the studies have been performed in an unselected population. Second, a phase III trial has demonstrated unacceptable toxicity of the combination of WBRT, SRS and erlotinib (76). Furthermore, in a recent randomized study, WBRT has been shown to impair cognitive function when added to SRS (86). Preservation of cognitive function is of major importance in these patients considering their younger age. In addition, studies evaluating the efficacy of gefitinib are mainly preformed in Asian populations, and it is unknown whether results can be globally generalized.

At this time, concurrent use of TKIs with radiotherapy is not recommended outside of a clinical trial. Interestingly, the data in EGFR mutant patients treated with erlotinib alone (47) prompt the question whether this could be a frontline approach in patients with asymptomatic BM, reserving WBRT for symptomatic cases. However, this should probably not be considered in ALK positive tumors, since patients with BM have been shown to have significantly better survival when treated with radiotherapy compared to patients with ALK WT tumors (87). These patients display prolonged survival and interventions to control intracranial disease is crucial (88). Therefore, radiotherapy should be a part of multimodality treatment somewhere in the course of their disease; it has been also suggested that the role of PCI could be reconsidered (89). In clinical practice, burden of extracranial disease and therefore concerns regarding disease flare might also guide treatment decisions; physicians might select not to discontinue a TKI during WBRT in case of extended extracranial disease.

Ongoing clinical trials are currently evaluating the effectiveness of concomitant use of radiotherapy and TKIs. Among them, ENTER is a phase III trial evaluating the addition of erlotinib to WBRT as front line treatment in patients with multiple BM from NSCLC (NCT01887795). Similarly, another study is assessing concurrent use of erlotinib and IMRT (NCT02556593), with the view to reduce neurotoxicity.

\section{Conclusions}

In conclusion, the incidence of BM from all cancers is increasing. Current research is focusing on improving management of BM based on genetic background of malignancies. In NSCLC, agents targeting EGFR and ALK have shown very promising results in systemic disease and delay of CNS progression. However, resistance to these agents commonly manifests as isolated CNS recurrence. In an attempt to improve management of BM, combining WBRT with TKIs is a promising approach. Because all these agents are relatively new, their role 
Table 1 Summary of trials of radiotherapy plus TKIs in patients with NSCLC and BM

\begin{tabular}{|c|c|c|c|c|c|c|}
\hline Author/year & Phase & No of pts & $\begin{array}{l}\text { EGFR mutation } \\
\text { status }\end{array}$ & Treatment groups & Control group & Outcomes \\
\hline $\begin{array}{l}\text { Lind et al., } \\
2009\end{array}$ & I & 11 & NA & $\begin{array}{l}\text { Cohort 1: erlotinib } 100 \\
\text { mg + WBRT; cohort } \\
\text { 2: erlotinib } 150 \mathrm{mg}+ \\
\text { WBRT }\end{array}$ & - & $\begin{array}{l}\text { Grade } 3-5 \text { toxicity in cohort } 2 \text {; high } \\
\text { IDCR }\end{array}$ \\
\hline $\begin{array}{l}\text { Welsh et al., } \\
2013\end{array}$ & II & 40 & $\begin{array}{l}\text { EGFR mutant: } 9 \\
\text { of } 17 \text { pts tested }\end{array}$ & $\begin{array}{l}\text { Erlotinib } 150 \mathrm{mg}+ \\
\text { WBRT }\end{array}$ & - & $\begin{array}{l}\text { ORR } 86 \% \text {; median OS } 11.8 \text { months; } \\
\text { median OS } 19.1 \text { months in EGFR } \\
\text { mutant }\end{array}$ \\
\hline $\begin{array}{l}\text { Sperduto } \\
\text { et al., } 2013\end{array}$ & III & $\begin{array}{l}126 \\
\text { (closed } \\
\text { early) }\end{array}$ & NA & $\begin{array}{l}\text { Arm 2: TMZ + WBRT } \\
\text { + SRS; arm 3: erlotinib } \\
150 \text { mg + WBRT + } \\
\text { SRS }\end{array}$ & $\begin{array}{l}\text { Arm 1: } \\
\text { WBRT + SRS }\end{array}$ & $\begin{array}{l}\text { OS not improved with addition of } \\
\text { drugs; no difference in CNS-TTP } \\
\text { between the three arms; } 49 \% \text { grade } \\
3-5 \text { toxicity in arm } 3\end{array}$ \\
\hline $\begin{array}{l}\text { Lee et al., } \\
2014\end{array}$ & II & 80 & $\begin{array}{l}\text { EGFR mutant: } 1 \\
\text { out of } 35 \text { tested }\end{array}$ & WBRT + erlotinib & WBRT & No difference in OS \\
\hline $\begin{array}{l}\text { Pesce et al., } \\
2012\end{array}$ & II & 59 & NA & $\begin{array}{l}\text { WBRT + gefitinib vs. } \\
\text { WBRT + TMZ }\end{array}$ & - & $\begin{array}{l}\text { Median OS } 6.3 \text { months (gefitinib } \\
\text { arm), } 4.9 \text { months (TMZ arm); } \\
\text { no relevant toxicity }\end{array}$ \\
\hline $\begin{array}{l}\text { Zeng et al., } \\
2012\end{array}$ & Retrospective & 90 & NA & WBRT + gefitinib & Gefitinib & $\begin{array}{l}\text { Higher ORR and OS with WBRT + } \\
\text { gefitinib }\end{array}$ \\
\hline $\begin{array}{l}\text { Luo et al., } \\
2015\end{array}$ & Meta-analysis & $\begin{array}{c}980 \\
\text { (8 trials) }\end{array}$ & NA & $\begin{array}{l}\text { Radiotherapy }+ \text { TKI } \\
\text { (TKI group) }\end{array}$ & $\begin{array}{l}\text { Radiotherapy or } \\
\text { radiotherapy + } \\
\text { chemotherapy } \\
\text { (non-TKI group) }\end{array}$ & $\begin{array}{l}\text { Higher RR, CNS-TTP and OS in } \\
\text { radiotherapy + TKI group; } \\
\text { no difference is serious AEs }\end{array}$ \\
\hline $\begin{array}{l}\text { Jiang et al., } \\
2016\end{array}$ & Meta-analysis & $\begin{array}{c}1,552 \\
(15 \text { trials })\end{array}$ & $\begin{array}{l}\text { Variable among } \\
15 \text { studies }\end{array}$ & Radiotherapy + TKI & $\begin{array}{l}\text { Radiotherapy or } \\
\text { radiotherapy + } \\
\text { chemotherapy }\end{array}$ & $\begin{array}{l}\text { Higher RR, DCR, CNS-TTP and OS } \\
\text { in radiotherapy + TKI group; } \\
\text { increased rate of any grade AEs }\end{array}$ \\
\hline
\end{tabular}

AEs, adverse events; CNS-TTP, time to central nervous system progression; DCR, disease control; EGFR, epidermal growth factor receptor, IDCR, intracranial disease control, NA, not available; ORR, overall response rate; OS, overall survival; RR, response rate; SRS, stereotactic radio surgery; TKI, tyrosine kinase inhibitor; TMZ, temozolomide; WBRT, whole brain radio therapy.

as part of multimodality treatment is not clarified yet. Therefore, clinical trials that include patients with BM are warranted to help clarify the optimal timing of TKIs and cranial radiotherapy in NSCLC, with the view to reserve neurocognitive function and improve clinical outcomes.

\section{Acknowledgements}

None.

\section{Footnote}

Conflicts of Interest: The authors have no conflicts of interest to declare.

\section{References}

1. Siegel RL, Miller KD, Jemal A. Cancer statistics, 2015. CA Cancer J Clin 2015;65:5-29.

2. Metro G, Chiari R, Ricciuti B, et al. Pharmacotherapeutic options for treating brain metastases in non-small cell lung cancer. Expert Opin Pharmacother 2015;16:2601-13.

3. Sperduto PW, Chao ST, Sneed PK, et al. Diagnosisspecific prognostic factors, indexes, and treatment outcomes for patients with newly diagnosed brain metastases: a multi-institutional analysis of 4,259 patients. Int J Radiat Oncol Biol Phys 2010;77:655-61.

4. Sperduto PW, Kased N, Roberge D, et al. Summary report on the graded prognostic assessment: an accurate and facile diagnosis-specific tool to estimate survival for patients with 
brain metastases. J Clin Oncol 2012;30:419-25.

5. Chua D, Krzakowski M, Chouaid C, et al. Whole-brain radiation therapy plus concomitant temozolomide for the treatment of brain metastases from non-small-cell lung cancer: a randomized, open-label phase II study. Clin Lung Cancer 2010;11:176-81.

6. Antonadou D, Paraskevaidis M, Sarris G, et al. Phase II randomized trial of temozolomide and concurrent radiotherapy in patients with brain metastases. J Clin Oncol 2002;20:3644-50.

7. Cortes J, Rodriguez J, Aramendia JM, et al. Front-line paclitaxelcisplatin-based chemotherapy in brain metastases from non-small-cell lung cancer. Oncology 2003;64:28-35.

8. Bernardo G, Cuzzoni Q, Strada MR, et al. First-line chemotherapy with vinorelbine, gemcitabine, and carboplatin in the treatment of brain metastases from nonsmall-cell lung cancer: a phase II study. Cancer Invest 2002;20:293-302.

9. Robinet G, Thomas P, Breton JL, et al. Results of a phase III study of early versus delayed whole brain radiotherapy with concurrent cisplatin and vinorelbine combination in inoperable brain metastasis of non-small-cell lung cancer: Groupe Francais de Pneumo-Cancerologie (GFPC) Protocol 95-1. Ann Oncol 2001;12:59-67.

10. Barlesi F, Gervais R, Lena H, et al. Pemetrexed and cisplatin as first-line chemotherapy for advanced nonsmall-cell lung cancer (NSCLC) with asymptomatic inoperable brain metastases: a multicenter phase II trial (GFPC 07-01). Ann Oncol 2011;22:2466-70.

11. Bailon O, Chouahnia K, Augier A, et al. Upfront association of carboplatin plus pemetrexed in patients with brain metastases of lung adenocarcinoma. Neuro Oncol 2012;14:491-5.

12. Zimmermann S, Dziadziuszko R, Peters S. Indications and limitations of chemotherapy and targeted agents in nonsmall cell lung cancer brain metastases. Cancer Treat Rev 2014;40:716-22.

13. Senan S, Brade A, Wang LH, et al. PROCLAIM: Randomized Phase III Trial of Pemetrexed-Cisplatin or Etoposide-Cisplatin Plus Thoracic Radiation Therapy Followed by Consolidation Chemotherapy in Locally Advanced Nonsquamous Non-Small-Cell Lung Cancer. J Clin Oncol 2016;34:953-62.

14. Jamal-Hanjani M, Spicer J. Epidermal growth factor receptor tyrosine kinase inhibitors in the treatment of epidermal growth factor receptor-mutant non-small cell lung cancer metastatic to the brain. Clin Cancer Res 2012;18:938-44.
15. Abbott NJ, Ronnback L, Hansson E. Astrocyte-endothelial interactions at the blood-brain barrier. Nat Rev Neurosci 2006;7:41-53.

16. Lockman PR, Mittapalli RK, Taskar KS, et al. Heterogeneous blood-tumor barrier permeability determines drug efficacy in experimental brain metastases of breast cancer. Clin Cancer Res 2010;16:5664-78.

17. Eichler AF, Loeffler JS. Multidisciplinary management of brain metastases. Oncologist 2007;12:884-98.

18. Patchell RA, Tibbs PA, Walsh JW, et al. A randomized trial of surgery in the treatment of single metastases to the brain. N Engl J Med 1990;322:494-500.

19. Noordijk EM, Vecht CJ, Haaxma-Reiche H, et al. The choice of treatment of single brain metastasis should be based on extracranial tumor activity and age. Int J Radiat Oncol Biol Phys 1994;29:711-7.

20. Andrews DW, Scott CB, Sperduto PW, et al. Whole brain radiation therapy with or without stereotactic radiosurgery boost for patients with one to three brain metastases: phase III results of the RTOG 9508 randomised trial. Lancet 2004;363:1665-72.

21. Aoyama H, Shirato H, Tago M, et al. Stereotactic radiosurgery plus whole-brain radiation therapy vs stereotactic radiosurgery alone for treatment of brain metastases: a randomized controlled trial. JAMA 2006;295:2483-91.

22. Kocher M, Soffietti R, Abacioglu U, et al. Adjuvant wholebrain radiotherapy versus observation after radiosurgery or surgical resection of one to three cerebral metastases: results of the EORTC 22952-26001 study. J Clin Oncol 2011;29:134-41.

23. Borgelt B, Gelber R, Kramer S, et al. The palliation of brain metastases: final results of the first two studies by the Radiation Therapy Oncology Group. Int J Radiat Oncol Biol Phys 1980;6:1-9.

24. Mulvenna PM, Nankivell MG, Barton R, et al. Whole brain radiotherapy for brain metastases from non-small lung cancer: Quality of life (QoL) and overall survival (OS) results from the UK Medical Research Council QUARTZ randomised clinical trial (ISRCTN 3826061). J Clin Oncol 2015;33:abstr 8005 .

25. Balm M, Hammack J. Leptomeningeal carcinomatosis. Presenting features and prognostic factors. Arch Neurol 1996;53:626-32.

26. Clarke JL, Perez HR, Jacks LM, et al. Leptomeningeal metastases in the MRI era. Neurology 2010;74:1449-54.

27. Zhou C, Wu YL, Chen G, et al. Erlotinib versus chemotherapy as first-line treatment for patients with 
advanced EGFR mutation-positive non-small-cell lung cancer (OPTIMAL, CTONG-0802): a multicentre, open-label, randomised, phase 3 study. Lancet Oncol 2011;12:735-42.

28. Mok TS, Wu YL, Thongprasert S, et al. Gefitinib or carboplatin-paclitaxel in pulmonary adenocarcinoma. $\mathrm{N}$ Engl J Med 2009;361:947-57.

29. Sequist LV, Yang JC, Yamamoto N, et al. Phase III study of afatinib or cisplatin plus pemetrexed in patients with metastatic lung adenocarcinoma with EGFR mutations. J Clin Oncol 2013;31:3327-34.

30. Gomez-Roca C, Raynaud CM, Penault-Llorca F, et al. Differential expression of biomarkers in primary nonsmall cell lung cancer and metastatic sites. J Thorac Oncol 2009;4:1212-20.

31. Italiano A, Vandenbos FB, Otto J, et al. Comparison of the epidermal growth factor receptor gene and protein in primary non-small-cell-lung cancer and metastatic sites: implications for treatment with EGFR-inhibitors. Ann Oncol 2006;17:981-5.

32. Matsumoto S, Takahashi K, Iwakawa R, et al. Frequent EGFR mutations in brain metastases of lung adenocarcinoma. Int J Cancer 2006;119:1491-4.

33. Eichler AF, Kahle KT, Wang DL, et al. EGFR mutation status and survival after diagnosis of brain metastasis in nonsmall cell lung cancer. Neuro Oncol 2010;12:1193-9.

34. Chen MJ, Zhong W, Zhang L, et al. Recurrence patterns of advanced non-small cell lung cancer treated with gefitinib. Chin Med J (Engl) 2013;126:2235-41.

35. Yoshida T, Yoh K, Niho S, et al. RECIST progression patterns during EGFR tyrosine kinase inhibitor treatment of advanced non-small cell lung cancer patients harboring an EGFR mutation. Lung Cancer 2015;90:477-83.

36. Lee YJ, Choi HJ, Kim SK, et al. Frequent central nervous system failure after clinical benefit with epidermal growth factor receptor tyrosine kinase inhibitors in Korean patients with nonsmall-cell lung cancer. Cancer 2010;116:1336-43.

37. Shukuya T, Takahashi T, Naito T, et al. Continuous EGFR-TKI administration following radiotherapy for non-small cell lung cancer patients with isolated CNS failure. Lung Cancer 2011;74:457-61.

38. Al-Halabi H, Sayegh K, Digamurthy SR, et al. Pattern of Failure Analysis in Metastatic EGFR-Mutant Lung Cancer Treated with Tyrosine Kinase Inhibitors to Identify Candidates for Consolidation Stereotactic Body Radiation Therapy. J Thorac Oncol 2015;10:1601-7.

39. Heon S, Yeap BY, Britt GJ, et al. Development of central nervous system metastases in patients with advanced non-small cell lung cancer and somatic EGFR mutations treated with gefitinib or erlotinib. Clin Cancer Res 2010;16:5873-82.

40. Togashi Y, Masago K, Masuda S, et al. Cerebrospinal fluid concentration of gefitinib and erlotinib in patients with non-small cell lung cancer. Cancer Chemother Pharmacol 2012;70:399-405.

41. Zhao J, Chen M, Zhong W, et al. Cerebrospinal fluid concentrations of gefitinib in patients with lung adenocarcinoma. Clin Lung Cancer 2013;14:188-93.

42. Fekrazad MH, Ravindranathan M, Jones DV 2nd. Response of intracranial metastases to erlotinib therapy. J Clin Oncol 2007;25:5024-6.

43. Popat S, Hughes S, Papadopoulos P, et al. Recurrent responses to non-small cell lung cancer brain metastases with erlotinib. Lung Cancer 2007;56:135-7.

44. Gounant V, Wislez M, Poulot V, et al. Subsequent brain metastasis responses to epidermal growth factor receptor tyrosine kinase inhibitors in a patient with non-small-cell lung cancer. Lung Cancer 2007;58:425-8.

45. Ceresoli GL, Cappuzzo F, Gregorc V, et al. Gefitinib in patients with brain metastases from non-small-cell lung cancer: a prospective trial. Ann Oncol 2004;15:1042-7.

46. Porta R, Sanchez-Torres JM, Paz-Ares L, et al. Brain metastases from lung cancer responding to erlotinib: the importance of EGFR mutation. Eur Respir J 2011;37:624-31.

47. Gerber NK, Yamada Y, Rimner A, et al. Erlotinib versus radiation therapy for brain metastases in patients with EGFR-mutant lung adenocarcinoma. Int J Radiat Oncol Biol Phys 2014;89:322-9.

48. Clarke JL, Pao W, Wu N, et al. High dose weekly erlotinib achieves therapeutic concentrations in CSF and is effective in leptomeningeal metastases from epidermal growth factor receptor mutant lung cancer. J Neurooncol 2010;99:283-6.

49. Jackman DM, Holmes AJ, Lindeman N, et al. Response and resistance in a non-small-cell lung cancer patient with an epidermal growth factor receptor mutation and leptomeningeal metastases treated with high-dose gefitinib. J Clin Oncol 2006;24:4517-20.

50. Hoffknecht P, Tufman A, Wehler T, et al. Efficacy of the irreversible ErbB family blocker afatinib in epidermal growth factor receptor (EGFR) tyrosine kinase inhibitor (TKI)-pretreated non-small-cell lung cancer patients with brain metastases or leptomeningeal disease. J Thorac Oncol 2015;10:156-63. 
51. Ballard P, Yates JW, Yang Z, et al. Preclinical Comparison of Osimertinib with Other EGFR-TKIs in EGFR-Mutant NSCLC Brain Metastases Models, and Early Evidence of Clinical Brain Metastases Activity. Clin Cancer Res 2016;22:5130-40.

52. Goss GD, Yang JC, Ahn MJ, et al. AZD9291 in pretreated patients with T790M positive advanced non-small cell lung cancer (NSCLC): Pooled analysis from two Phase II studies. Eur J Cancer 2015;51:S640.

53. Ahn MJ, Tsai CM, Yang JC, et al. AZD9291 activity in patients with EGFR-mutant advanced non-small cell lung cancer (NSCLC) and brain metastases: Data from Phase II studies. Eur J Cancer 2015;51:S625-26.

54. Yang CH, Kim DW, Kim SW, et al. Osimertinib activity in patients (pts) with leptomeningeal (LM) disease from non-small cell lung cancer (NSCLC): Updated results from BLOOM, a phase I study. J Clin Oncol 2016;34:abstr 9002.

55. Patel S, Rimner A, Foster A, et al. Risk of Brain Metastasis in EGFR-Mutant NSCLC Treated With Erlotinib: A Role for Prophylactic Cranial Irradiation? : Metastatic Non-Small Cell Lung Cancer. Int J Radiat Oncol Biol Phy 2014;90:S40-41.

56. Li N, Zeng ZF, Wang SY, et al. Randomized phase III trial of prophylactic cranial irradiation versus observation in patients with fully resected stage IIIA-N2 nonsmallcell lung cancer and high risk of cerebral metastases after adjuvant chemotherapy. Ann Oncol 2015;26:504-9.

57. Zhang I, Zaorsky NG, Palmer JD, et al. Targeting brain metastases in ALK-rearranged non-small-cell lung cancer. Lancet Oncol 2015;16:e510-21.

58. Costa DB, Kobayashi S, Pandya SS, et al. CSF concentration of the anaplastic lymphoma kinase inhibitor crizotinib. J Clin Oncol 2011;29:e443-5.

59. Metro G, Lunardi G, Floridi P, et al. CSF Concentration of Crizotinib in Two ALK-Positive Non-Small-Cell Lung Cancer Patients with CNS Metastases Deriving Clinical Benefit from Treatment. J Thorac Oncol 2015;10:e26-7.

60. Costa DB, Shaw AT, Ou SH, et al. Clinical Experience With Crizotinib in Patients With Advanced ALKRearranged Non-Small-Cell Lung Cancer and Brain Metastases. J Clin Oncol 2015;33:1881-8.

61. Shaw A, Mehra R, Tan DSW, et al. Ceritinib (LDK378) for treatment of patients with ALK-rearranged (ALK+) non-small cell lung cancer (NSCLC) and brain metastases (BM) in the ASCEND-1 trial. Neuro Oncol 2014;16:v39.

62. Seto T, Kiura K, Nishio M, et al. CH5424802 (RO5424802) for patients with ALK-rearranged advanced non-small-cell lung cancer (AF-001JP study): a single-arm, open-label, phase 1-2 study. Lancet Oncol 2013;14:590-8.

63. Gadgeel SM, Gandhi L, Riely GJ, et al. Safety and activity of alectinib against systemic disease and brain metastases in patients with crizotinib-resistant ALK-rearranged non-small-cell lung cancer (AF-002JG): results from the dose-finding portion of a phase 12 study. Lancet Oncol 2014;15:1119-28.

64. Ahn HK, Han B, Lee SJ, et al. ALK inhibitor crizotinib combined with intrathecal methotrexate treatment for non-small cell lung cancer with leptomeningeal carcinomatosis. Lung Cancer 2012;76:253-4.

65. Soon YY, Leong CN, Koh WY, et al. EGFR tyrosine kinase inhibitors versus cranial radiation therapy for EGFR mutant non-small cell lung cancer with brain metastases: a systematic review and meta-analysis. Radiother Oncol 2015;114:167-72.

66. Iuchi T, Shingyoji M, Sakaida T, et al. Phase II trial of gefitinib alone without radiation therapy for Japanese patients with brain metastases from EGFR-mutant lung adenocarcinoma. Lung Cancer 2013;82:282-7.

67. Bonner JA, Harari PM, Giralt J, et al. Radiotherapy plus cetuximab for squamous-cell carcinoma of the head and neck. N Engl J Med 2006;354:567-78.

68. Bradley JD, Paulus R, Komaki R, et al. Standard-dose versus high-dose conformal radiotherapy with concurrent and consolidation carboplatin plus paclitaxel with or without cetuximab for patients with stage IIIA or IIIB non-small-cell lung cancer (RTOG 0617): a randomised, two-by-two factorial phase 3 study. Lancet Oncol 2015;16:187-99.

69. Chinnaiyan P, Huang S, Vallabhaneni G, et al. Mechanisms of enhanced radiation response following epidermal growth factor receptor signaling inhibition by erlotinib (Tarceva). Cancer Res 2005;65:3328-35.

70. Liang K, Ang KK, Milas L, et al. The epidermal growth factor receptor mediates radioresistance. Int J Radiat Oncol Biol Phys 2003;57:246-54.

71. Baumann M, Krause M, Dikomey E, et al. EGFR-targeted anti-cancer drugs in radiotherapy: preclinical evaluation of mechanisms. Radiother Oncol 2007;83:238-48.

72. Zeng YD, Liao H, Qin T, et al. Blood-brain barrier permeability of gefitinib in patients with brain metastases from non-small-cell lung cancer before and during whole brain radiation therapy. Oncotarget 2015;6:8366-76.

73. Lind JS, Lagerwaard FJ, Smit EF, et al. Phase I study of concurrent whole brain radiotherapy and erlotinib for multiple brain metastases from non-small-cell lung cancer. 
Int J Radiat Oncol Biol Phys 2009;74:1391-6.

74. Welsh JW, Komaki R, Amini A, et al. Phase II trial of erlotinib plus concurrent whole-brain radiation therapy for patients with brain metastases from non-small-cell lung cancer. J Clin Oncol 2013;31:895-902.

75. Lu Y, Fan Y. Combined action of EGFR tyrosine kinase inhibitors and whole-brain radiotherapy on EGFRmutated non-small-cell lung cancer patients with brain metastasis. Onco Targets Ther 2016;9:1135-43.

76. Sperduto PW, Wang M, Robins HI, et al. A phase 3 trial of whole brain radiation therapy and stereotactic radiosurgery alone versus WBRT and SRS with temozolomide or erlotinib for non-small cell lung cancer and 1 to 3 brain metastases: Radiation Therapy Oncology Group 0320. Int J Radiat Oncol Biol Phys 2013;85:1312-8.

77. Lee SM, Lewanski CR, Counsell N, et al. Randomized trial of erlotinib plus whole-brain radiotherapy for NSCLC patients with multiple brain metastases. J Natl Cancer Inst 2014;106.

78. Liu L, Yang M, Guan J, et al. Whole Brain Radiotherapy (WBRT) plus EGFR tyrosine kinase inhibitors (TKIs) versus WBRT alone for brain metastases (BMs) in nonsmall cell lung cancer (NSCLC) patients: A meta-analysis. J Clin Oncol 2015;35:e19060.

79. Ma S, Xu Y, Deng Q, et al. Treatment of brain metastasis from non-small cell lung cancer with whole brain radiotherapy and Gefitinib in a Chinese population. Lung Cancer. 2009;65:198-203.

80. Pesce GA, Klingbiel D, Ribi K, et al. Outcome, quality of life and cognitive function of patients with brain metastases from non-small cell lung cancer treated with whole brain radiotherapy combined with gefitinib or temozolomide. A randomised phase II trial of the Swiss Group for Clinical Cancer Research (SAKK 7003). Eur J Cancer 2012;48:377-84.

81. Zeng YD, Zhang L, Liao H, et al. Gefitinib alone or with concomitant whole brain radiotherapy for

Cite this article as: Economopoulou P, Mountzios G. Nonsmall cell lung cancer (NSCLC) and central nervous system (CNS) metastases: role of tyrosine kinase inhibitors (TKIs) and evidence in favor or against their use with concurrent cranial radiotherapy. Transl Lung Cancer Res 2016;5(6):588-598. doi: 10.21037/tlcr.2016.12.06 patients with brain metastasis from non-small-cell lung cancer: a retrospective study. Asian Pac J Cancer Prev 2012;13:909-14.

82. Luo S, Chen L, Chen X, et al. Evaluation on efficacy and safety of tyrosine kinase inhibitors plus radiotherapy in NSCLC patients with brain metastases. Oncotarget 2015;6:16725-34.

83. Jiang T, Min W, Li Y, et al. Radiotherapy plus EGFR TKIs in non-small cell lung cancer patients with brain metastases: an update meta-analysis. Cancer Med 2016;5:1055-65.

84. Kwak EL, Bang YJ, Camidge DR, et al. Anaplastic lymphoma kinase inhibition in non-small-cell lung cancer. N Engl J Med 2010;363:1693-703.

85. Chaft JE, Oxnard GR, Sima CS, et al. Disease flare after tyrosine kinase inhibitor discontinuation in patients with EGFR-mutant lung cancer and acquired resistance to erlotinib or gefitinib: implications for clinical trial design. Clin Cancer Res 2011;17:6298-303.

86. Brown PD, Jaeckle K, Ballman KV, et al. Effect of Radiosurgery Alone vs Radiosurgery With Whole Brain Radiation Therapy on Cognitive Function in Patients With 1 to 3 Brain Metastases: A Randomized Clinical Trial. JAMA 2016;316:401-9.

87. Mak KS, Gainor JF, Niemierko A, et al. Significance of targeted therapy and genetic alterations in EGFR, ALK, or KRAS on survival in patients with non-small cell lung cancer treated with radiotherapy for brain metastases. Neuro Oncol 2015;17:296-302.

88. Johung KL, Yeh N, Desai NB, et al. Extended Survival and Prognostic Factors for Patients With ALK-Rearranged Non-Small-Cell Lung Cancer and Brain Metastasis. J Clin Oncol 2016;34:123-9.

89. Copur MS, Ramaekers R, Clark D. Is It Time to Reconsider Prophylactic Cranial Radiation in Non-SmallCell Lung Cancer? J Clin Oncol 2016;34:2314. 